\title{
Hydrogen Adsorption Properties of Nano- and Microstructures of $\mathrm{ZnO}$
}

\author{
Rizwan Wahab, ${ }^{1}$ Farheen Khan, ${ }^{2}$ Naushad Ahmad, ${ }^{3}$ Hyung-Shik Shin, ${ }^{4}$ \\ Javed Musarrat, ${ }^{5}$ and Abdulaziz A. Al-Khedhairy ${ }^{1}$ \\ ${ }^{1}$ Department of Zoology, College of Science, King Saud University, Riyadh 11451, Saudi Arabia \\ ${ }^{2}$ Department of Chemistry, Aligarh Muslim University, Aligarh, Uttar Pradesh 202002, India \\ ${ }^{3}$ Department of Chemistry, College of Science, King Saud University, Riyadh 11451, Saudi Arabia \\ ${ }^{4}$ Energy Materials \& Surface Science Laboratory, Solar Energy Research Center, School of Chemical Engineering, \\ Chonbuk National University, Jeonju 561-756, Republic of Korea \\ ${ }^{5}$ Department of Agricultural Microbiology, Faculty of Agricultural Sciences, Aligarh Muslim University, Aligarh 202002, India
}

Correspondence should be addressed to Rizwan Wahab; rwahab@ksu.edu.sa

Received 16 May 2013; Revised 31 August 2013; Accepted 10 September 2013

Academic Editor: Xuedong Bai

Copyright (C) 2013 Rizwan Wahab et al. This is an open access article distributed under the Creative Commons Attribution License, which permits unrestricted use, distribution, and reproduction in any medium, provided the original work is properly cited.

\begin{abstract}
Nanoparticles, microflowers, and microspheres of zinc oxide have been synthesized in a large quantity via solution process at low temperature and were tested for the hydrogen adsorption studies. The experiments were carried out using Sievert's apparatus which resulted in highest hydrogen adsorption value for nanoparticles is $\sim 1.220 \mathrm{wt} \%$, whereas for microflower composed with thin sheets value reduced $(\sim 1.011 \mathrm{wt} \%)$ but in case of microspheres composed with nanoparticles having below one wt\% ( 0.966 wt $\%)$. The FE-SEM and XRD clarify that the obtained products are crystalline with wurtzite phase. Including morphological and crystalline characterization, the surface area of the prepared nano- and microstructures was observed with BET.
\end{abstract}

\section{Introduction}

Hydrogen $\left(\mathrm{H}_{2}\right)$ is the most valuable and convenient energy source, which holds tremendous properties due to its high energy density. It is a clean, environmental friendly versatile source of energy that can be transformed to a desired form, without releasing harmful emissions $[1,2]$. Since it is free from air pollution and greenhouse gas therefore, attracted a great deal of attention towards a green energy regime $[1,2]$. Analyses have concluded that "most of the hydrogen supply chain path releases significantly less carbon dioxide into the atmosphere than the gasoline used in the hybrid electric vehicles" and thus leads to the significant reduction in carbon dioxide emission. The mass and volume density problems associated with hydrogen/molecular hydrogen storage are the current barrier to practical storage schemes. The properties of hydrogen storage in materials were assessed for automotive applications, due to its low cost, high gravimetric and volumetric density, fast kinetics, proper thermodynamics and low temperature dissociation/decomposition properties, and long-term stability. Numerous metal hydrides, chemical hydrides, adsorbents, and the nanomaterials have been used for hydrogen storage purposes [3-9]. Till date, the fulfillment of hydrogen storage criteria from these materials does not reach their high $\mathrm{H}_{2}$ content. The hydrogen content is very less and it is below $6 \mathrm{wt} \%$ [10]. Nanostructured materials have potential capacity due to their high surface area and adsorption properties on the surface and can easily influence thermo dynamics and kinetics of hydrogen adsorption $[9,10]$. It can offer the possibility of controlling and tailoring the parameters independently of their bulk counterparts. Due to high surface area it offers various advantages for the physicochemical reactions such as surface interactions, adsorptions, rapid kinetics, low-temperature sorption, hydrogen atom dissociation, and molecular diffusion via the surface catalyst $[9,10]$. Several reports have been published to explore the approaches on to absorb molecular hydrogen onto a solid storage material. CNTs are recently studied for hydrogen storage purpose due to its excellent physical, chemical, and electronic properties $[1,2]$. The hydrogen adsorption capacity 


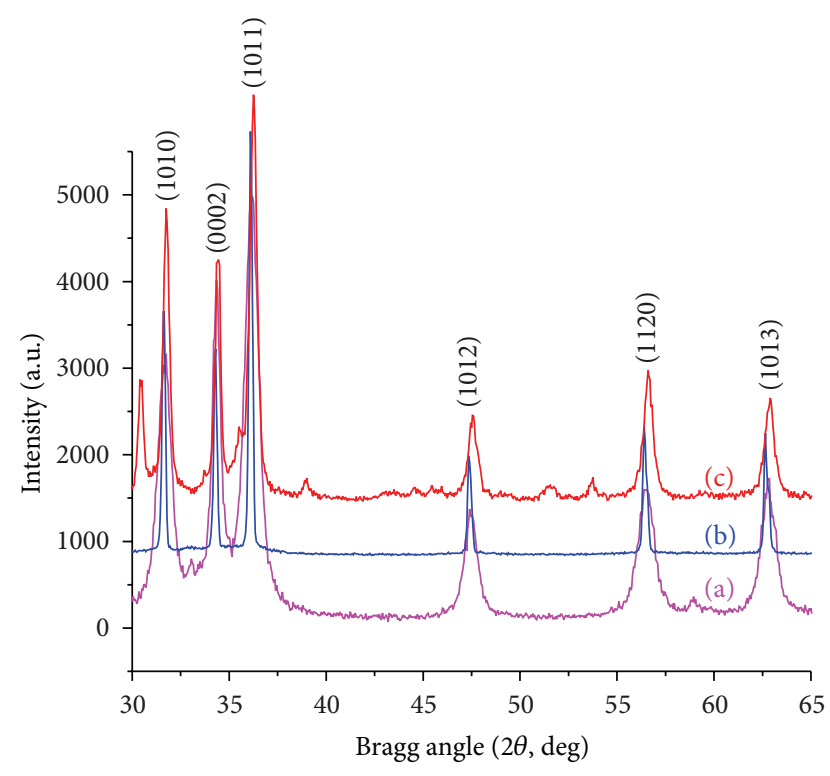

FIgURE 1: Typical XRD of (a) nanoparticles, (b) microflowers, and (c) microspheres.

of SWCNTs was also studied at $133 \mathrm{~K}$, for pure SWCNTs as 5 to 10 weight \% [11]. Apart from nanotubes, incredible efforts are being paid to investigate the unexplored properties of semiconductor nanostructure materials [12]. Due to few reports have been published on metal oxide nanostructures for hydrogen storage purposes such as the hydrogen storage capacity of $\mathrm{ZnO}$ nanowires prepared by thermal evaporation of metallic zinc at room temperature is about 0.83 weight $\%$ by Wan et al. [13]. The nanostructures of $\mathrm{ZnO}$ increase our interest much after Wang report [14], which explores $\mathrm{H}_{2}$ storage properties of $\mathrm{ZnO}$ nanostructures. The nanostructure of zinc oxide now exhibits a variety of nanostructures, and hence it is believed to be the richest family of nanostructures [14]. Abundant applications have already been set in this field such as light emitting diode, field-effect transistor, ultraviolet nanolasers, solar cells, and acoustic electrical device gas sensors, using $\mathrm{ZnO}$, and many more needs to be investigated $[15,16]$. It has a variety of nanostructures such as nanowires, nanobelts, nanobridges, nanonails, nanoribbons, nanorods, nanotubes, and whiskers prepared with various techniques and it is reported in the literature [17-21]. Till date the preparation of nanostructures via soft chemical solution process provides an easy and convenient route with better yield for large-scale production of nanocrystals. The present report shows a preliminary study of $\mathrm{H}_{2}$ adsorption properties at room temperatures with the use of nano- and microstructures of $\mathrm{ZnO}$, synthesized via simple solution process.

\section{Materials and Methods}

2.1. Material Synthesis and Their Characterization. Synthesis of diverse shaped zinc oxide nanostructures such as nanoparticles, microflowers which is composed with thin sheets, and microspheres composed with nanoparticles were carried out at different conditions by using various precursors and divided into three steps as follows.

(a) Synthesis of Nanoparticles ( $\mathrm{ZnO}$-NPs). The synthesis of $\mathrm{ZnO}-\mathrm{NPs}$ was performed with using zinc acetate dihydrate $\left(\mathrm{Zn}(\mathrm{Ac})_{2} \cdot 2 \mathrm{H}_{2} \mathrm{O}\right)$ and octadecylamine $\left(\mathrm{CH}_{3}\left(\mathrm{CH}_{2}\right)_{17} \mathrm{NH}_{2}\right)$. In a typical experiment $0.3 \mathrm{M}$ zinc acetate dihydrate $\left(\mathrm{Zn}(\mathrm{Ac})_{2} \cdot 2 \mathrm{H}_{2} \mathrm{O}\right)$ was dissolved in $100 \mathrm{~mL}$ methanol with octadecylamine $\left(3 \times 10^{-2} \mathrm{M}\right)$. The obtained solution was stirred for $30 \mathrm{~min}$ for the complete dissolution. The $\mathrm{pH}$ of solution $\mathrm{pH}$ reached up to $\sim 12.3$. The complete dissolution of the mixture was transferred to the refluxing pot, and refluxed at $\sim 65^{\circ} \mathrm{C}$ for $6 \mathrm{~h}$. Before six hours no precipitate was observed in the refluxing pot but after six hours white colored solution appeared in the refluxing pot. After refluxing, the white precipitated powder was washed with methanol several times for to remove the ionic impurities and dried at room temperature.

(b) Synthesis of Microflower Composed with Thin Flakes ( $\mathrm{ZnO}$ TFs). The microflowers composed with thin flakes ( $\mathrm{ZnO}-$ TFs) were obtained with the use of precursor zinc nitrate hexahydrate, hydroxylamine hydrochloride, sodium hydroxide, and (+) L-cysteine. In a typical experiment, zinc nitrate hexahydrate $\left(\mathrm{Zn}\left(\mathrm{NO}_{3}\right)_{2} \cdot 6 \mathrm{H}_{2} \mathrm{O}\right)(0.3 \mathrm{M})$, hydroxyl lamine hydrochloride $\left(\mathrm{NH}_{2} \mathrm{OH} \cdot \mathrm{HCl}\right)(1 \mathrm{M})$, and sodium hydroxide $(0.3 \mathrm{M})$ were dissolved in $100 \mathrm{~mL}$ of distilled water and stirred for $30 \mathrm{~min}$ in a $250 \mathrm{~mL}$ capacity for the complete dissolution. The $\mathrm{pH}$ of this solution was measured with the use of $\mathrm{pH}$ meter and it reaches up to 12.6. To this solution (+) L-cysteine was mixed and again checked the $\mathrm{pH}$ of this solution. The $\mathrm{pH}$ of this solution was dropped from 12.6 to 8.31 and the solution color turned to light yellowish. The stirred solution was transferred to the refluxing pot at $\sim 95^{\circ} \mathrm{C}$ for $12 \mathrm{hrs}$. The white thicky precipitate was obtained, washed with methanol several times to remove the ionic impurities, and dried on a petri dish at room temperature for further analysis.

(c) Synthesis of Microspheres Composed with Tiny Nanoparticles ( $\mathrm{ZnO}-\mathrm{MSs})$. The fabrication of zinc oxide microspheres composed with tiny nanoparticles ( $\mathrm{ZnO}-\mathrm{MSs}$ ) was performed via using zinc nitrate hexahydrate ( $\mathrm{Zn}$ $\left.\left(\mathrm{NO}_{3}\right)_{2} \cdot 6 \mathrm{H}_{2} \mathrm{O}\right),(+)$ L-cysteine, and hexa methylenetetramine (HMT), $\left(\mathrm{C}_{6} \mathrm{H}_{12} \mathrm{~N}_{4}\right)$. In a typical experiment $0.3 \mathrm{M}$ zinc nitrate hexahydrate, $0.1 \mathrm{M}$ hexamethylenetetramine (HMT), and $1 \times 10^{-2} \mathrm{M}(+)$ L-cysteine were dissolved in $80 \mathrm{~mL}$ of distilled water under constant stirring. To this solution, $20 \mathrm{~mL}$ of sodium hydroxide $(\mathrm{NaOH})(0.1 \mathrm{M})$ was incorporated to increase the basicity of the solution and the $\mathrm{pH}$ value of this solution was 8.85 obtained at this time. After the complete dissolution, white thick mixture was transferred in Teflonlined stainless steel autoclaves at $95^{\circ} \mathrm{C}$ in 6 hours. The obtained precipitate was washed with methanol several times to remove the ionic impurities, dried at room temperature, and examined in terms of their structural and chemical properties.

The general morphology of prepared samples was observed using FE-SEM. For the analysis of FE-SEM, nano and microstructures of zinc oxide were uniformly sprayed 


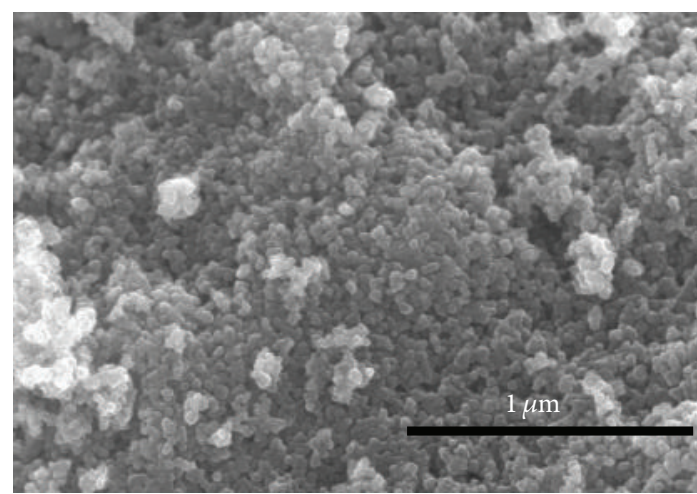

(a)

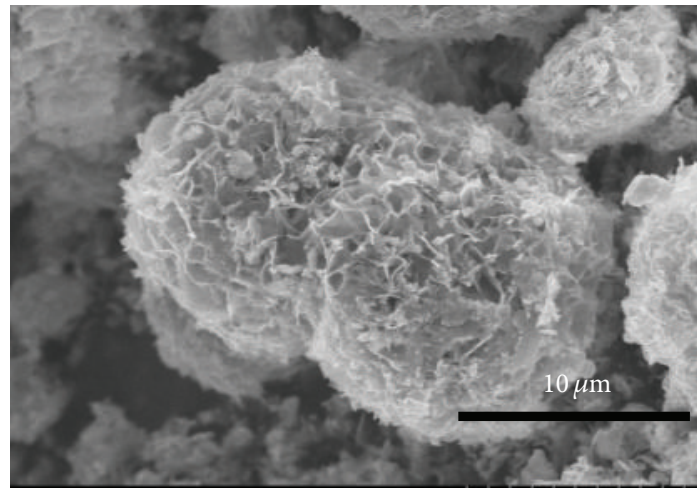

(c)

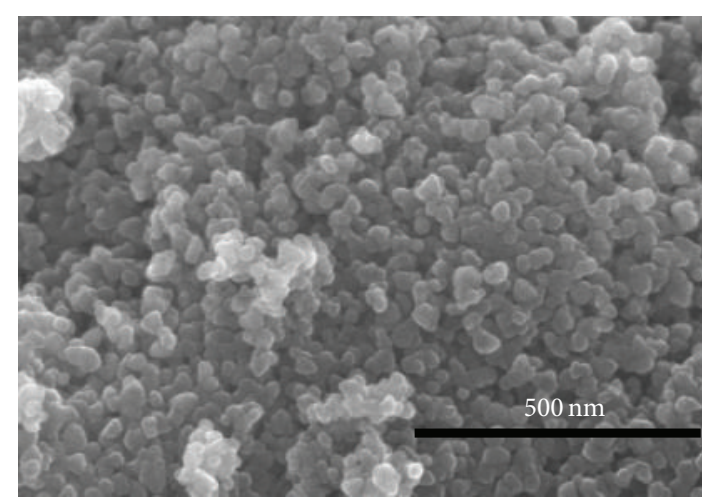

(b)

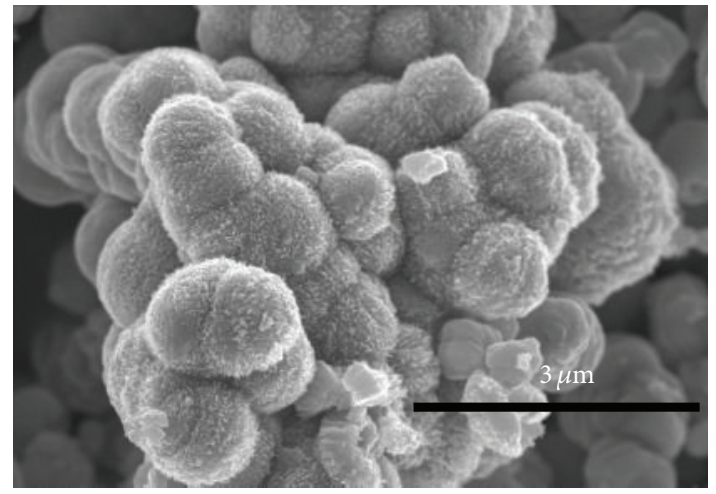

(d)

FiguRE 2: FE-SEM images of nano- and microstructures: (a)-(b) nanoparticles, (c) microflowers, and (d) microspheres.

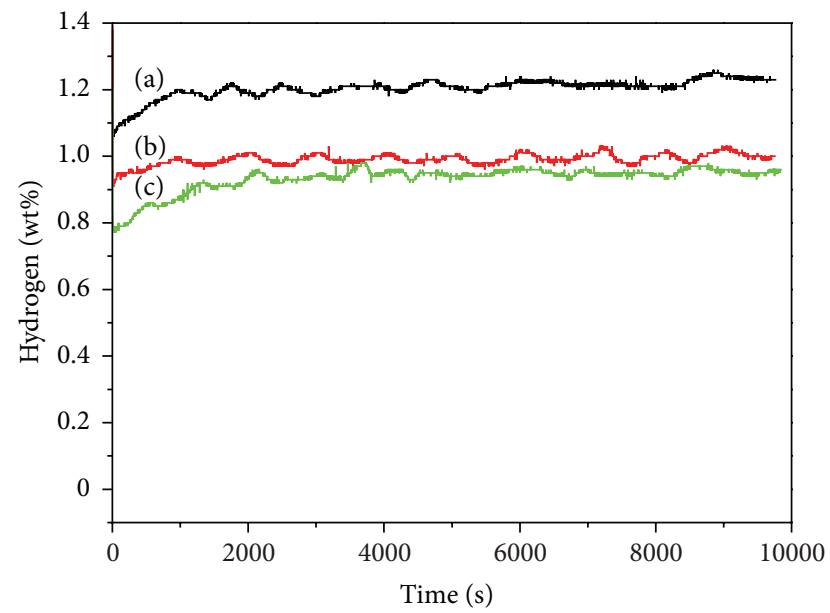

FIGURE 3: Hydrogen adsorption of nano- and microstructures: (a) nanoparticles, (b) microflowers, and (c) microspheres.

on the carbon tape. The samples were coated with $\sim 10 \mathrm{~nm}$ thin Pt layer before FE-SEM observation to avoid charging while observation. The crystallinity and crystal phases were determined by X-ray powder diffraction (XRD) with $\mathrm{CuK} \alpha$ radiation $\left(\lambda=1.54178 \AA\right.$ ) with Bragg angle ranging from $20^{\circ}$ to $65^{\circ}$. Including the basic characterization, the surface area of the materials was measured by using the instrument ASAP
2010 (mentics, USA). The sample weights were measured as $0.1121 \mathrm{~g}, 0.1222$ and $0.1356 \mathrm{~g}$ under $\mathrm{N}_{2}$ atmosphere with degassing temperature $250^{\circ} \mathrm{C}$ overnight.

2.2. Hydrogen Adsorption Study. The hydrogen adsorption studies of nano- and microstructures of $\mathrm{ZnO}$ were evaluated using conventional volumetric pressure-composition (P-C) isothermal method using an automated Sievert's type gas reaction controller (GRC) apparatus as per our previously published paper [22].

\section{Results and Discussion}

3.1. Structural (FE-SEM) and Crystalline (XRD) Analysis of Materials. Figure 1 shows the X-ray diffraction pattern of nanoparticles, microflowers composed with flakes, and microspheres composed with tiny nanoparticles at the above prepared conditions using precursor zinc nitrate hexahydrate, octa decylamine $\left(\mathrm{CH}_{3}\left(\mathrm{CH}_{2}\right)_{17} \mathrm{NH}_{2}\right),(+)$ L-cysteine, hexamethylenetetramine (HMT), and sodium hydroxide $(\mathrm{NaOH})$. The obtained diffraction peaks are well matched with the lattice constants of zinc oxide $\mathrm{a}=3.249$ and $\mathrm{c}=$ $5.206 \AA$. All the data fully agree with the standard data Joint Committee on Powder Diffraction Standards (JCPDS 361451). The intense peaks with narrow HW FM suggest the good crystallinity of $\mathrm{ZnO}$. In our data, there is no impurity peak observed in the $\mathrm{X}$-ray diffraction pattern except zinc 


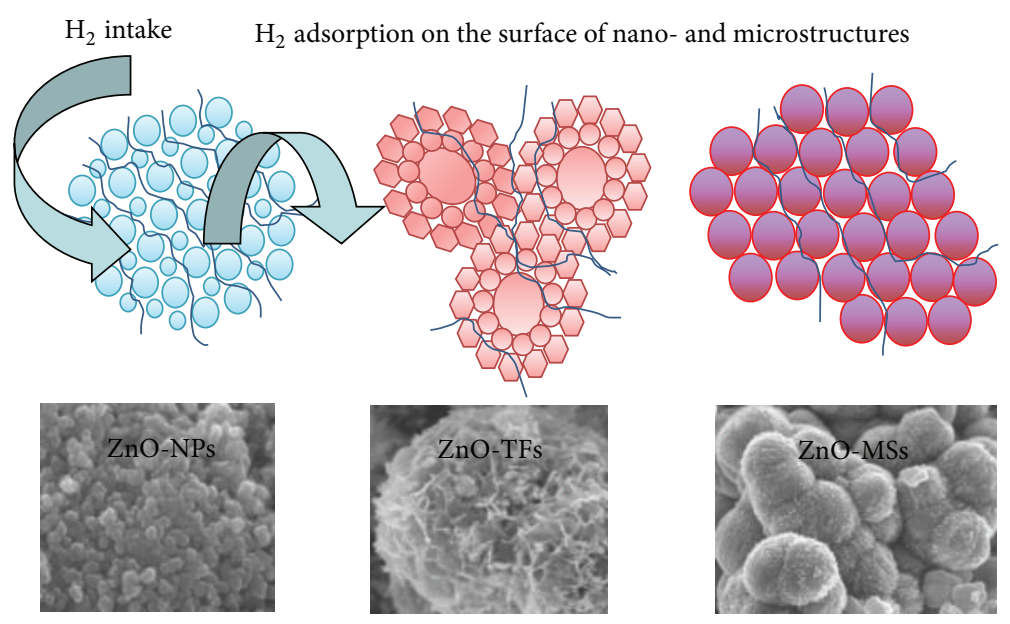

FIGURE 4: Schematic presentation of hydrogen intake on the surface of nano- and microstructures.

oxide. After the analysis of crystallinity of the grown materials, the morphology of the prepared nanostructures of zinc oxide such as nanoparticles, microflowers, and microspheres was observed via field emission electron microscopy (FESEM). Figures 2(a) and 2(b) show the low and high magnified images of $\mathrm{ZnO}-\mathrm{NPs}$ processed with the use of precursor zinc salts and octa decylamine at the above conditions. From the images, it is clearly depicted that the grown NPs are in spherical shape with an aggregated form. The size of each nanoparticle (NP) of zinc oxide is seen very small, which is about $\sim 10-15 \mathrm{~nm}$. The observation of grain size is clearly consistent with the FE-SEM and X-ray diffraction patterns (Figure 1). Figure 2(c) shows the image of $\mathrm{ZnO}$ microflowers composed with thin flasks obtained at the above condition. The images clearly show that the thickness of flower thin sheets is about $\sim 5-10 \mathrm{~nm}$ and the diameter is in the range of $2-3 \mu \mathrm{m}$. Figure $2(\mathrm{~d})$ is the image of microspheres composed with tiny NPs, and the spheres are made up with the conjugation of several tiny nanoparticles. The diameter of each surfaced NP is in the range of $\sim 10 \mathrm{~nm}$ in size. The FE-SEM images indicate that the estimate diameter of each individual microsphere conjugated with small NPs is $1-1.5 \mu \mathrm{m}$ (Figure 2(d)).

3.2. Hydrogen Adsorption Studies. The hydrogen adsorption studies of the synthesized structures of $\mathrm{ZnO}$ were performed as a function of time at room temperature (Figure 3). The hydrogen storage capacity of prepared nanoparticles of zinc oxide is $\sim 1.220 \mathrm{wt} \%$, whereas the storage capacity decreases in microflower composed with thin flasks $(\sim 1.011 \mathrm{wt} \%)$. There is a small change that appeared in hydrogen adsorption data microspheres composed with nanoparticles, which is $\sim 0.966 \mathrm{wt} \%$. From the data, it is evident that at higher surface area, the adsorption is higher. A comparatively higher adsorption in nanoparticles is probably due to higher surface area, and it decreases in micro-flower composed with thin flasks which provides an easy path way to hydrogen diffusion into the interstitial cavities [11] and interlayer diffusion. In microspheres composed with nanoparticles having a solid sphere and that's why the hydrogen capacity decreases. Zinc oxide is well known for its wide applications in different areas. The dangling bonds on the surface of semiconductors are saturated by sharing their dangling electrons with the oxygen present in an ambient environment and equilibrium is established on the surface. Oxygen is adsorbed on the surface of the semiconductor by taking an electron from the conduction band. Any process that disturbs this equilibrium gives rise to changes in the conductance. This change can be correlated with the concentration of gases adsorbed. Physisorption and chemisorptions are the important processes responsible for the corresponding adsorption/desorption studies. The chemisorptions may dominate the storage process due to the formation of interstitial hydrogen in $\mathrm{ZnO}$. It is clearly indicated that higher surface areas are favorable for hydrogen incorporation in $\mathrm{ZnO}$ (Figure 3). However, the exact mechanism is not very clear. Wan et al. reported that bondcentered and antibonding configurations are close in energy for isolated interstitial hydrogen to form an $\mathrm{O}-\mathrm{H}$ bond based on the density functional theory [13], while $\mathrm{H}_{2}$ molecular complexes prefer a location in the interstitial channel, centered on the antibonding $\mathrm{Zn}$ site. However, the formation of a strong $\mathrm{O}-\mathrm{H}$ bond results in an irreversible process at room temperature. Including other characterizations, surface properties of the prepared nano- and microstructures were also measured. The Brunauer-Emmett-Teller (BET) surface area of the prepared samples were analyzed and listed in Table 1 . It can be clearly seen that the pores are located in the range between 45 and $63 \mathrm{~nm}$, indicating that the materials exhibit mesoporous property, which is in a good agreement to adsorb and desorb the hydrogen molecule $\left(\mathrm{H}_{2}\right)$ in nanoand microstructures of $\mathrm{ZnO}$. As we can compare, each sample surface area first increases and then decreases. In case of $\mathrm{ZnO}-\mathrm{NPs}$, they are having enough space to adsorb and pass the $\mathrm{H}_{2}$ on surface. The microflowers ( $\mathrm{ZnO}$-TFs) have very thin sheets ( $5-10 \mathrm{~nm}$, thickness), which is suitable to pass the $\mathrm{H}_{2}$, but due to the big size of microstructures $(\sim 2-3 \mu \mathrm{m})$ it takes time to move the $\mathrm{H}_{2}$ and that is why the adsorption capacity is less as compared to $\mathrm{ZnO}-\mathrm{NPs}$. In case of 
TABLE 1: The BET surface area of nano- and microstructures.

\begin{tabular}{lccc}
\hline Material & $\begin{array}{c}\text { Crystalline } \\
\text { type }\end{array}$ & $\begin{array}{c}\text { BET surface } \\
\text { area }\left(\mathrm{m}^{2} \cdot \mathrm{g}^{-1}\right)\end{array}$ & $\begin{array}{c}\text { Particle size } \\
(\mathrm{nm}) \text { from } \\
\text { FE-SEM }\end{array}$ \\
\hline $\mathrm{ZnO}-\mathrm{NPs}$ & Wurtzite & 50 & $\sim 10-15 \mathrm{~nm}$ \\
$\mathrm{ZnO}-\mathrm{TFs}$ & Wurtzite & 63 & $\sim 2-3 \mu \mathrm{m}$ \\
$\mathrm{ZnO}-\mathrm{MSs}$ & Wurtzite & 45 & $\sim 1-1.5 \mu \mathrm{m}$ \\
\hline
\end{tabular}

microspheres (ZnO-MSs, $(\sim 1-1.5 \mu \mathrm{m}))$ composed with small NPs, which are highly agglomerated and tightly bonded with other NPs. These NPs exhibit small pores between adjacent NPs. Due to agglomeration, size of microstructures ( 1$1.5 \mu \mathrm{m})$ and insufficient space between two adjacent NPs are having less $\mathrm{H}_{2}$ adsorption as compared to other nanostructures. The pictorial schematic diagram clearly describes the hydrogen intake on the surface of nano- and microstructures (Figure 4) [23, 24].

\section{Conclusions}

In summary, we have compared the hydrogen adsorption studies of fabricated nano- and microstructures of different shaped zinc oxide nanostructures via simple solution method at low-temperature refluxing range in a very short period. The investigations revealed that the fabricated structures are crystalline and possess a wurtzite hexagonal phase. The X-ray diffraction demonstrates that the synthesized products are in high crystallinity with good chemical properties. Including these properties hydrogen storage studies of solution grown nanostructures (microflowers, microspheres, and nanoparticles) make a prominent material for further applications in fuel cells. Apart from X-ray diffraction and FE-SEM, the hydrogen adsorption study is in a good agreement with the surface characterization.

\section{Acknowledgment}

Rizwan Wahab would like to extend the appreciation to the Deanship of Scientific Research at King Saud University for funding the work through the research group project no. RGP-VPP-218.

\section{References}

[1] C. Liu, Y. Y. Fan, M. Liu, H. T. Cong, H. M. Cheng, and M. S. Dresselhaus, "Hydrogen storage in single-walled carbon nanotubes at room temperature," Science, vol. 286, no. 5442, pp. 1127-1129, 1999.

[2] S.-U. Rather, R. Zacharia, S. W. Hwang, M.-U. Naik, and K. S. Nahm, "Hyperstoichiometric hydrogen storage in monodispersed palladium nanoparticles," Chemical Physics Letters, vol. 438, no. 1-3, pp. 78-84, 2007.

[3] S. Satyapal, J. Petrovic, and G. Thomas, "Gassing up with hydrogen,” Scientific American, vol. 296, no. 4, pp. 80-87, 2007.
[4] M. S. Dresselhaus and I. L. Thomas, "Alternative energy technologies," Nature, vol. 414, no. 6861, pp. 332-337, 2001.

[5] B. Sakintuna, F. Lamari-Darkrim, and M. Hirscher, "Metal hydride materials for solid hydrogen storage: a review," International Journal of Hydrogen Energy, vol. 32, no. 9, pp. 1121-1140, 2007.

[6] A. M. Seayad and D. M. Antonell, "Recent advances in hydrogen storage in metal-containing inorganic nanostructures and related materials," Advanced Materials, vol. 16, no. 9-10, pp. 765777, 2004.

[7] F. E. Pinkerton and B. G. Wicke, "Bottling the hydrogen genie," The Industrial Physicist, vol. 10, no. 1, pp. 20-23, 2004.

[8] F. Schüth, "Hydrogen and hydrates," Nature, vol. 434, no. 7034, pp. 712-713, 2005.

[9] F. Sclüth, B. Bogdanović, and M. Felderhoff, "Light metal hydrides and complex hydrides for hydrogen storage," Chemical Communications, vol. 10, no. 20, pp. 2249-2258, 2004.

[10] A. G. Wong-Foy, A. J. Matzger, and O. M. Yaghi, "Exceptional $\mathrm{H}_{2}$ saturation uptake in microporous metal-organic frameworks," Journal of the American Chemical Society, vol. 128, no. 11, pp. 3494-3495, 2006.

[11] A. Chambers, C. Park, R. T. K. Baker, and N. M. Rodriguez, "Hydrogen storage in grap-hite nanofibers," The Journal of Physical Chemistry B, vol. 102, pp. 4253-4256, 1998.

[12] M. H. Huang, S. Mao, H. Feick et al., "Room-temperature ultraviolet nanowire nanolasers," Science, vol. 292, no. 5523, pp. 1897-1899, 2001.

[13] Q. Wan, C. L. Lin, X. B. Yu, and T. H. Wang, "Room-temperature hydrogen storage characteristics of $\mathrm{ZnO}$ nanowires," Applied Physics Letters, vol. 84, no. 1, pp. 124-126, 2004.

[14] Z. L. Wang, "Nanostructures of zinc oxide," Materials Today, vol. 7, no. 6, pp. 26-33, 2004.

[15] Y. Chen, D. M. Bagnall, H.-J. Koh et al., "Plasma assisted molecular beam epitaxy of $\mathrm{ZnO}$ on c-plane sapphire: growth and characterization," Journal of Applied Physics, vol. 84, no. 7, pp. 3912-3918, 1998.

[16] G. Sberveglieri, S. Groppelli, P. Nelli, A. Tintinelli, and G. Giunta, "A novel method for the preparation of $\mathrm{NH}_{3}$ sensors based on ZnO-In thin films," Sensors and Actuators B, vol. 25, no. 1-3, pp. 588-590, 1995.

[17] Z. W. Pan, Z. R. Dai, and Z. L. Wang, "Nanobelts of semiconducting oxides," Science, vol. 291, no. 5510, pp. 1947-1949, 2001.

[18] Y. J. Xing, Z. H. Xi, Z. Q. Xue et al., "Optical properties of the $\mathrm{ZnO}$ nanotubes synthesized via vapor phase growth," Applied Physics Letters, vol. 83, no. 9, pp. 1689-1691, 2003.

[19] S. Y. Li, C. Y. Lee, and T. Y. Tseng, "Copper-catalyzed ZnO nanowires on silicon ( $\left.\begin{array}{lll}1 & 0 & 0\end{array}\right)$ grown by vapor-liquid-solid process," Journal of Crystal Growth, vol. 247, no. 3-4, pp. 357362, 2003.

[20] R. Wahab, S. G. Ansari, Y. S. Kim et al., "Low temperature solution synthesis and characterization of $\mathrm{ZnO}$ nano-flowers," Materials Research Bulletin, vol. 42, no. 9, pp. 1640-1648, 2007.

[21] R. Wahab, S. G. Ansari, Y.-S. Kim, H.-K. Seo, and H.-S. Shin, "Room temperature synthesis of needle-shaped $\mathrm{ZnO}$ nanorods via sonochemical method," Applied Surface Science, vol. 253, no. 18, pp. 7622-7626, 2007.

[22] R. Wahab, Z. A. Ansari, S. G. Ansari et al., "Hydrogen storage properties of heterostructured zinc oxide nanostructures," Journal of Nanoengineering and Nanomanufacturing, vol. 1, pp. 188195, 2011. 
[23] D. Ramimoghadam, M. Z. B. Hussein, and Y. H. Taufiq-Yap, "Hydrothermal synthesis of zinc oxide nanoparticles using rice as soft biotemplate," Chemistry Central Journal, vol. 7, pp. 136145, 2013.

[24] D. Ramimoghadam, M. Z. B. Hussein, and Y. H. Taufiq-Yap, "The effect of sodium dodecyl sulfate (SDS) and cetyltrimethylammonium bromide (CTAB) on the properties of $\mathrm{ZnO}$ synthesized by hydrothermal method," International Journal of Molecular Sciences, vol. 13, pp. 13275-13293, 2012. 

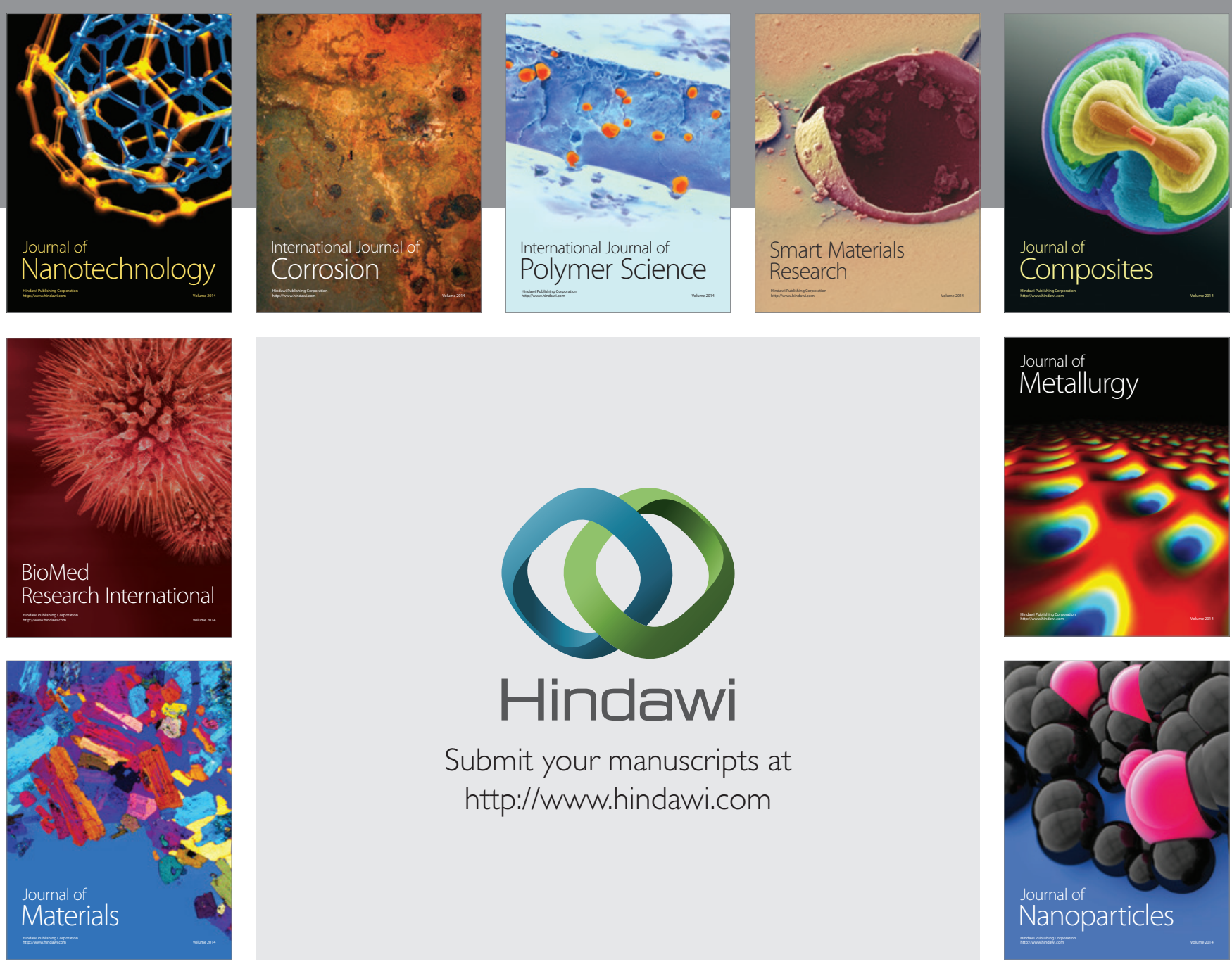

Submit your manuscripts at http://www.hindawi.com
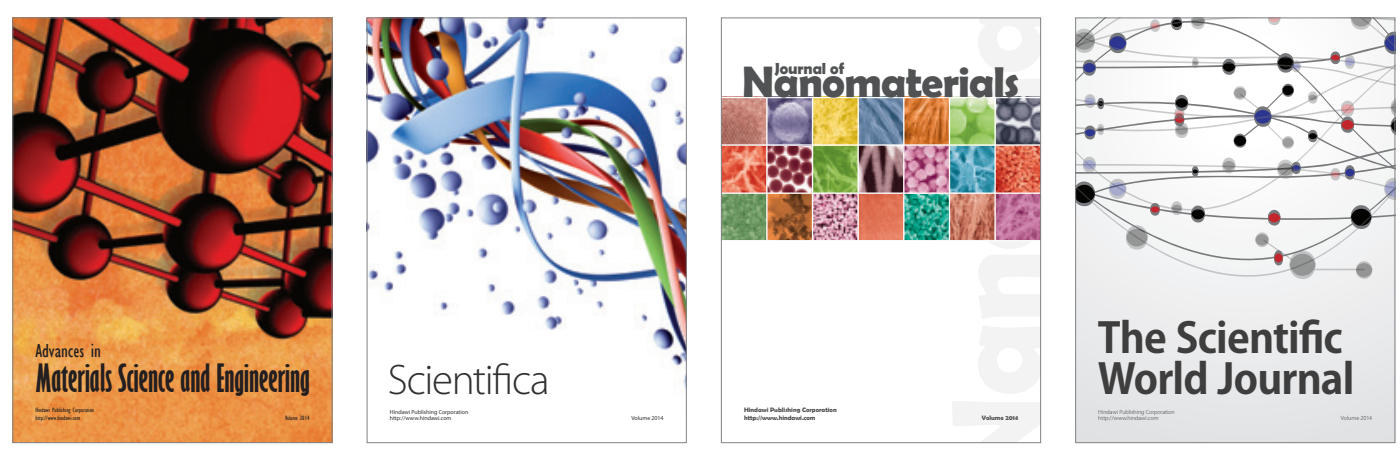

\section{The Scientific World Journal}
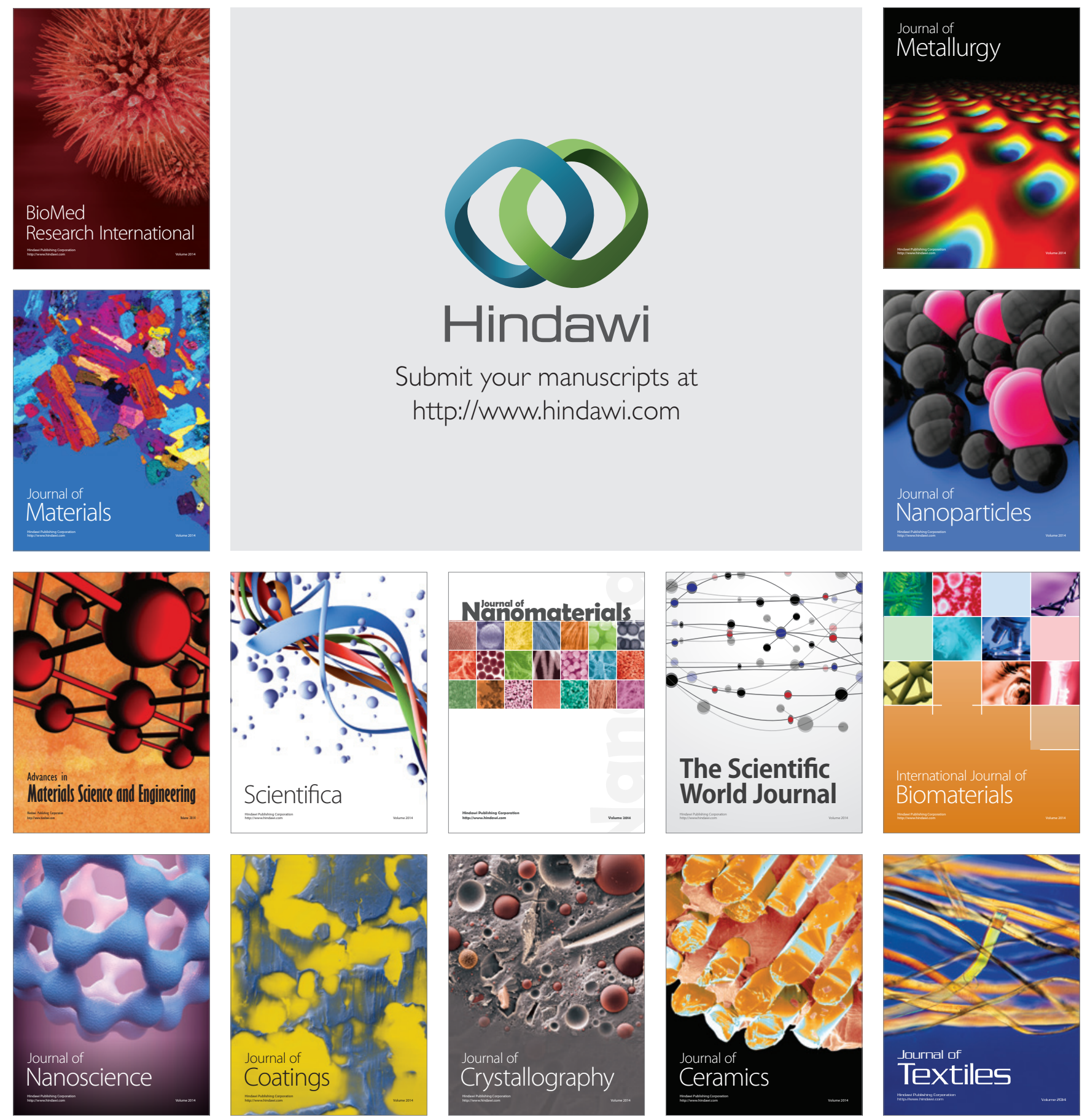